\title{
Implementasi Metode Triple Exponential Smoothing Untuk Prediksi Penjualan Alat Kesehatan
}

\author{
Ratih Yulia Hayuningtyas \\ Teknik Informatika, Sekolah Tinggi Manajemen Informatika dan Komputer Nusa Mandiri \\ Indonesia
}

Email : ratih.ryl@nusamandiri.ac.id

\begin{abstract}
Easy Touch Kolestrol Strip is one of medical device sought after medical device by medical staff and pharmacies because it is very helpful in checking health. The large demand for these goods, so that the stock of goods becomes out of control and there is an increase in demand at certain times resulting in customer needs not fulfilled. The incraese in demand occurs because there is no estimated number of sales, so there is a need to review the number of sales. For this reason, a forecasting method is needed that can provide a forecast value of the number of goods sold in the following month. In this study, the Triple Exponential Smoothing method uses alpha constants from 0,1 to 0,5. The results of this test produce the smallest error value by looking at Mean Absolute Deviation, Mean Square Error, and Mean Absolute Percentage Error. The smallest error value obtained from the alpha constant value of 0,1 with a MAPE result of 0,33\%.
\end{abstract}

\section{Keywords: Triple Exponential Smoothing; Forecasting}

\begin{abstract}
Abstrak
Easy Touch Kolestrol Strip salah satu alat kesehatan yang banyak dicari oleh tenaga medis maupun apotik karena sangat membantu dalam mengecek kesehatan. Banyaknya permintaan akan barang tersebut, sehingga membuat stok barang menjadi tidak terkendali dan terjadi kenaikan permintaan pada saat tertentu yang mengakibatkan kebutuhan pelanggan tidak terpenuhi. Kenaikan permintaan terjadi karena tidak ada estimasi jumlah pernjualan sehingga perlu adanya kajian ulang terhadap jumlah penjualan. Untuk itu diperlukannya suatu metode peramalan yang dapat memberikan nilai ramalan tentang jumlah penjualan barang pada bulan berikutnya. Pada penelitian ini menggunakan metode Triple Exponential Smoothing yang menggunakan nilai konstanta alpha 0,1 sampai dengan 0,5. Hasil dari pengujian ini menghasilkan nilai kesalahan terkecil dengan melihat Mean Absolute Deviation, Mean Square Error, dan Mean Absolute Percentage Error. Nilai kesalahan terkecil didapat dari nilai konstanta alpha 0,1 dengan hasil MAPE 0,33\%.
\end{abstract}

\section{Kata Kunci: Triple Exponential Smoothing; Peramalan}

\section{Introduction}

Alat kesehatan merupakan salah satu alat yang tidak dapat terpisahkan oleh kesehatan manusia, dikarenakan alat kesehatan ini sangat membantu bagi para medis untuk mengecek kesehatan manusia. Sebagai 
contoh yaitu Easy Touch Kolestrol Strip, banyak sekali tenaga medis atau apotik yang sudah menggunakan alat ini untuk mengecek kesehatan.

Banyaknya permintaan akan barang tersebut, sehingga membuat stok barang menjadi tidak terkendali. Terjadinya kenaikan permintaan pada saat tertentu sehingga banyak pelanggan yang tidak dapat terpenuhi kebutuhannya. Kenaikan permintaan terjadi karena tidak ada estimasi jumlah penjualan sehingga perlu adanya kajian ulang terhadap jumlah penjualan..

Untuk mengendalikan jumlah penjualan, dibutuhkan suatu metode peramalan. Dimana metode peramalan ini akan memberikan nilai ramalan mengenai jumlah penjualan barang pada bulan berikutnya. Dengan adanya metode ini diharapkan dapat memenuhi permintaan barang oleh pelanggan.

Peramalan merupakan suat cara yang digunakan untuk menstimulasi data yang akan datang dengan melihat data lampau (Utami \& Atmojo, 2017). Metode ini memiliki tujuan yaitu memanfaatkan data masa lalu untuk memprediksi data dimasa yang akan datang sebagai upaya untuk mengambil suatu keputusan yang lebih baik.

Pada penelitian ini menggunakan metode Triple Exponential Smoothing, merupakan metode yang sering digunakan sebagai peramalan dikarenakan memiliki konsep dan perhitungan yang sederhana (Rossetti, 2019). Salah satu alasan digunakannya metode smoothing data deret berkala karena metode ini dapat dilakukan dengan dua pendekatan yaitu metode perataan dan metode exponential smoothing (Jayanti, Atmojo, \& Wiadnyana, 2015).

Sudah dilakukan penelitian sebelumnya mengenai peramalan penjualan Cream Det Ekonomi pada PT. Dinamika Daya Segara Malang menggunakan metode Triple Exponential Smoothing dengan hasil kesalahan terkecil pada nilai alpha 0,1 dengan MAPE 10,04\% (Tistiawan \& Andini, 2019) . Pada tahun 2018 dilakukan penelitian tentang peramalan persediaan obat menggunakan metode Triple Exponential Smoothing pada RSUD Kab, Muna menghasilkan MAPE 4,25\% dengan nilai alpha 0,1 (Nangi, Indrianti, \& Pramono, 2018).

Tujuan dari penelitian ini yaitu memprediksi jumlah penjualan dimasa yang akan datang menggunakan metode Triple Exponential Smoothing dengan mencari kesalahan terkecil melalui Mean Absolute Percentage Error yang diuji dengan nilai konstanta alpha.

\section{Materials and Methods}

\section{A. Peramalan}

Ramalan memiliki arti yaitu situasi atau kondisi yang diperkirakan akan terjadi pada 
masa yang akan datang, sedangkan peramalan merupakan bentuk kegiatannya (Fitria \& Hartono, 2017). Peramalan menghasilkan perkiraan yang jarang salah dan memiliki kesalahan perkiraan kecil (Ishaque \& Ziblim, 2013).

\section{B. Metode Exponential Smoothing}

Smoothing yaitu mengambil rata-rata dari nilai pada periode tertentu untuk menaksir suatu periode (Fitria \& Hartono, 2017). Exponential Smoothing merupakan prosedur yang secara terus menerus memperbaiki peramalan dengan merata-rata (menghaluskan=smoothing) pada nilai masa lalu dari data runtut waktu dengan cara menurun (exponential) (Mardiansyah, Cahyono, \& Shanty, 2016).

Metode peramalan exponential menggunakan konstanta yang menetapkan bobot untuk permintaan saat ini dan perkiraan sebelumnya untuk mendapatkan perkiraan yang akan dating (Ravinder, 2013). Exponential Smoothing dapat diterapkan pada data deret waktu, baik untuk menghasilkan data presentasi smoothing atau membuat peramalan (Margaret \& Jose, 2015).

\section{Triple Exponential Smoothing}

Metode ini merupakan metode forecast yang dikemukakan oleh Brown, dengan menggunakan persamaan kuadrat (Subagyo, 2013). Triple Exponential Smoothing merupakan perluasan dari teknik exponential ganda linier dua parameter Holt atas musiman dengan menyertakan penghalusan ketiga untuk disesuaikan (Sinaga, Sagala, \& Sijabat, 2016).

Metode Triple Exponential Smoothing memiliki kelebihan yaitu dalam analisis dilakukan tiga kali pemulusan sehingga diperoleh hasil peramalan yang baik (Gurianto, Purnamasari, \& Yuniarti, 2016).

Pembuatan forecast dengan metode Triple Exponential Smoothing sebagai berikut (Subagyo, 2013):

1. Mencari nilai $S_{t}$

$$
S^{\prime} \mathrm{t}=\alpha X \mathrm{t}+(1-\alpha) S^{\prime} \mathrm{t}-1
$$

2. Mencari nilai $\mathrm{S}_{\mathrm{t}}$

$$
S^{\prime \prime} \mathrm{t}=\alpha S^{\prime} \mathrm{t}+(1-\alpha) S^{\prime \prime} \mathrm{t}-1
$$

3. Mencari Nilai $S_{t}$,

$$
S^{\prime \prime \prime} \mathrm{t}=\alpha S^{\prime \prime} \mathrm{t}+(1-\alpha) S^{\prime \prime \prime} \mathrm{t}-1
$$

4. Mencari Nilai $a_{t}$

$$
a \mathrm{t}=3 \mathrm{~S}^{\prime \prime} \mathrm{t}-3 \mathrm{~S}^{x \prime} \mathrm{t}+\mathrm{S}^{\prime \prime \prime} \mathrm{t}
$$

5. Mencari Nilai $b_{t}$

$$
b \mathrm{t}=\frac{\alpha}{2(1-\alpha)^{2}}\left[(6-5 \alpha) S^{\prime} \mathrm{t}-(10-8 \alpha) S^{\prime \prime} \mathrm{t}+(4-3 \alpha) \mathrm{S}^{\prime \prime \prime} \mathrm{t}\right]
$$

6. Mencari Nilai $c_{t}$

$$
b \mathrm{t}=\frac{\alpha^{2}}{(1-\alpha)^{2}}\left(\mathrm{~S}^{\prime \prime} \mathrm{t}-2 \mathrm{~S}^{\prime \prime} \mathrm{t}+\mathrm{S}^{\prime \prime \prime} \mathrm{t}\right)
$$

7. Persamaan Forecast

$$
F t+m=a t+b t m+\frac{1}{2} c t m^{2}
$$

Pada rumus diatas untuk menghasilkan nilai forecast melalui beberapa tahapan, dimana $S$ 't yaitu nilai pemulusan exponential pertama dan $\mathrm{Xt}$ nilai data aktual. S't adalah nilai pemulusan exponential kedua dan S','t nilai pemulusan exponential ketiga. Sedangkan at, bt, ct 
merupakan nilai konstanta pemulusan dan alpha adalah nilai parameter pemulusan yang besarnya dari 0 samapi dengan 1. Pada persamaan forecast nilai $\mathrm{m}$ yaitu jumlah periode yang diramalkan dan Ft yaitu data peramalan.

\section{Akurasi Peramalan}

Untuk mengetahui keakuratan metode peramalan data yang telah dilakukan dengan cara menghitung nilai data aktual dikurangin dengan data peramalannya yaitu Mean Absolute Deviation (MAD), Mean Squared Error (MSE) dan Mean Absolute Percentage Error (MAPE) (Nangi et al., 2018).

\section{Mean Absolute Deviation (MAD)} merupakan kesalahan absolut yang menyatakan peyimpangan ramalan dalam unit yang sama pada data, dengan cara merata-ratakan nilai absolute error dari seluruh hasil peramalan (Wahyuni \& Lestio, 2019)

$M A D=\sum \frac{[\text { Actual }- \text { peramala }]}{n}$

Mean Squared Error (MSE) merupakan metode yang menghasilkan kesalahankesalahan yang memungkinkan lebih baik. Mean Squared Error merupakan rata-rata selisih kuadrat antara nilai yang diramalkan dan nilai aktual (Margi S \& Pendawa W, 2015). Persamaan Mean Squared Error sebagai berikut:
$M S E=\sum_{t=1}^{n} \frac{(X t-F t)^{2}}{n}$

Mean Absolute Percentage Error (MAPE) yaitu rata-rata persentase kesalahan absolut yang dihitung dengan mencari nilai absolut galat disetiap periode yang dibagi dengan nilai aktual dan absolut galat persentase (Gurianto et al., 2016). Mean Absolute Percentage Error dapat dinyatakan dalam persamaan sebagai berikut:

MAPE $=\frac{1}{n}\left(\left(\sum_{t=1}^{n} \frac{|X t-F t|}{X t}\right) \times 100 \%\right.$

\section{Results and Discussion}

Pada toko alat kesehatan banyak barang yang dijual, salah satu yang dijadikan contoh pada penelitian ini yaitu alat kesehatan Easy Touch Kolestrol Strip dengan data penjualan sebagai berikut:

Tabel 1. Data Easy Touch Kolestrol Strip (2016)

\begin{tabular}{cc}
\hline Bulan & Data Penjualan \\
\hline Januari & 2 \\
\hline Februari & 52 \\
\hline Maret & 47 \\
\hline April & 44 \\
\hline Mei & 38 \\
\hline Juni & 36 \\
\hline Juli & 36 \\
\hline Agustus & 51 \\
\hline September & 41 \\
\hline Oktober & 52 \\
\hline November & 54 \\
\hline Desember & 51
\end{tabular}




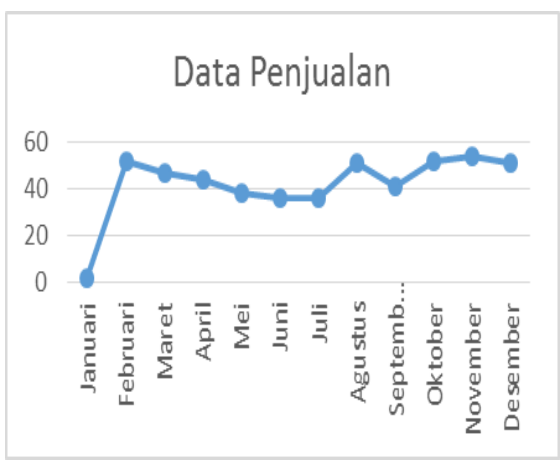

Gambar 1. Grafik data Penjualan

Easy Touch Kolestrol Strip (2016)
Pada penelitian ini mencoba mencari keakurasian peramalan dengan nilai Mean Absolute Percentage Error terkecil dan nilai alpha yang digunakan pada penelitian ini yaitu 0,1 sampai dengan 0,5 . Berikut adalah hasil dari peramalan menggunakan nilai alpha 0,1 .

Tabel 2. Perhitungan Forecasting dengan nilai alpha 0,1

\begin{tabular}{|c|c|c|c|c|c|c|c|c|}
\hline Periode & Data Penjualan & S't & S''t & S''t & at & bt & ct & Forecast \\
\hline Januari & 2 & 2,00 & 2,00 & 2,00 & 2,00 & 0,00 & 0,00 & 0,00 \\
\hline Februari & 52 & 7,00 & 2,50 & 2,05 & 15,55 & 1,68 & 0,05 & 2,00 \\
\hline Maret & 47 & 11,00 & 3,35 & 2,18 & 25,13 & 2,99 & 0,08 & 17,26 \\
\hline April & 44 & 14,30 & 4,45 & 2,41 & 31,97 & 4,04 & 0,10 & 28,16 \\
\hline Mei & 38 & 16,67 & 5,67 & 2,73 & 35,74 & 4,73 & 0,10 & 36,06 \\
\hline Juni & 36 & 18,60 & 6,96 & 3,16 & 38,08 & 5,24 & 0,10 & 40,52 \\
\hline Juli & 36 & 20,34 & 8,30 & 3,67 & 39,80 & 5,66 & 0,09 & 43,37 \\
\hline Agustus & 51 & 23,41 & 9,81 & 4,28 & 45,08 & 6,49 & 0,10 & 45,51 \\
\hline September & 41 & 25,17 & 11,35 & 4,99 & 46,46 & 6,85 & 0,09 & 51,62 \\
\hline Oktober & 52 & 27,85 & 13,00 & 5,79 & 50,35 & 7,49 & 0,09 & 53,35 \\
\hline November & 54 & 30,47 & 14,74 & 6,69 & 53,85 & 8,07 & 0,09 & 57,89 \\
\hline Desember & 51 & 32,52 & 16,52 & 7,67 & 55,66 & 8,44 & 0,09 & 61,97 \\
\hline
\end{tabular}

Dari tabel 2 maka dapat dicari data forecast untuk periode selanjutnya yaitu Januari 2017 sebagi berikut:

$$
\begin{aligned}
& F t+m=a t+b t m+\frac{1}{2} c t m^{2} \\
& \mathrm{Ft}=55,66+8,44(1)+\left(0,09 *(1)^{2}\right) / 2 \\
& \mathrm{Ft}=64,145
\end{aligned}
$$

Dari data diatas maka dapat diketahui peramalan untuk periode selanjutnya yaitu 64,145 dengan nilai aplha 0,1 .

Setelah menghitung nilai forecast maka dapat dicari nilai Mean Absolute Deviation,
Mean Square Error dan nilai Mean Absolute Percentage Error untuk mengetahui tingkat error terkecil dari nilai alpha yang digunakan yaitu 0,1 sampai dengan 0,5 dapat dilihat pada tabel 3 .

Tabel 3. Nilai MAE, MSE, MAPE dengan nilai alpha 0,1 sampai dengan 0,5

\begin{tabular}{ccccc}
\hline $\begin{array}{c}\text { Nilai } \\
\text { alpha }\end{array}$ & Forecast & MAD & MSE & MAPE \\
\hline 0,1 & 64,15 & 5,52 & 333,21 & 0,33 \\
\hline 0,2 & 70,72 & $-7,73$ & 490,69 & 0,50 \\
\hline 0,3 & 69,26 & $-14,43$ & 751,94 & 0,62 \\
\hline 0,4 & 67,11 & $-18,46$ & 1106,57 & 0,71 \\
\hline 0,5 & 65,24 & $-21,55$ & 1675,57 & 0,78 \\
\hline
\end{tabular}


Tabel 3 merupakan hasil perhitungan dari Mean Absolute Deviation, Mean Square Error dan nilai Mean Absolute Percentage Error dengan nilai error terkecil pada nilai alpha 0,1 dengan nilai MAD 11,98, MSE 333,21 dan nilai MAPE 0,33\%. Mencari nilai MAD, MSE, dan MAPE sebagai berikut:

$$
\begin{aligned}
& \text { MAD }=\sum \frac{[\text { Actual }- \text { peramalan }]}{n} \\
& \text { MAD }=143,75 / 12 \\
& \text { MAD }=11,98 \\
& M S E=\sum_{t=1}^{n} \frac{(X t-F t)^{2}}{n} \\
& \text { MSE }=3998,48 / 12 \\
& \text { MSE }=333,21 \\
& \text { MAPE }=\frac{1}{n}\left(\sum_{t=1}^{n} \frac{|X t-F t|}{X t}\right) \times 100 \% \\
& \text { MAPE }=4,02 / 12 \\
& \text { MAPE }=0,335
\end{aligned}
$$

\section{Conclusions}

Berdasarkan hasil pengujian yang dilakukan pada penelitian ini menggunakan metode Triple Exponential Smoothing dengan nilai konstanta alpha 0,1 sampai dengan 0,5 memperoleh nilai tingkat kesalahan terkecil pada nilai konstanta alpha 0,1. Hasil dari kesalahan terkecil terlihat dari MAPE dengan nilai $0,335 \%$. Penggunaan metode Triple Exponential Smoothing cukup efektif dan efisien untuk sebuah peramalan sehingga dapat memperkirakan jumlah persediaan yang akan datang untuk mengantisipasi banyaknya permintaan dalam penjualan.

\section{References}

Fitria, V. A., \& Hartono, R. (2017). Peramalan Jumlah Penumpang Pada Siluet Tour And Travel Kota Malang Menggunakan Metode Triple Exponential Smoothing. Jurnal Ilmiah Teknologi Informasi Asia, 11(1), 1520.

https://doi.org/10.32815/jitika.v11i1.35 Gurianto, R. N., Purnamasari, I., \& Yuniarti, D. (2016). Peramalan Jumlah Penduduk Kota Samarinda Dengan Menggunakan Metode Pemulusan Eksponensial Ganda dan Tripel Dari Brown. Eksponensial [S.l.], v. 7, N. 1, P. 23-32, Nov. 2017. ISSN 2085-7829., 7, No 1, 23-32.

Ishaque, M., \& Ziblim, S. D. (2013). Use of Some Exponential Smoothing Models in Forecasting Some Food Crop Prices in the Upper East Region of Ghana. Mathematical Theory and Modeling, 3(7), 16-28.

Jayanti, N. K. D. A., Atmojo, Y. P., \& Wiadnyana, I. G. N. (2015). Penerapan Metode Triple Exponential Smoothing Pada Sistem Peramalan Penentuan Stok Obat. Jurnal Sistem Dan Informatika, 9(2), 13-23.

Mardiansyah, E., Cahyono, D., \& Shanty, R. N. T. (2016). Sistem Informasi Pengendali Persediaan Barang Menggunakan Metode Triple Exponential Smoothing Untuk Peramalan Penjualan ( Studi Kasus: Luna Pet Shop ). INFORM, 1(2), 7687.

Margaret, V., \& Jose, J. (2015). Exponential Smoothing Models for Prediction of Solar Irradiance. International Journal of Advanced Research in Electrical, Electronics and Instrumentation 
Engineering, 4(2), 1133-1139.

Margi S, K., \& Pendawa W, S. (2015). Analisa Dan Penerapan Metode Single Exponential Smoothing Untuk Prediksi Penjualan Pada Periode Tertentu. Prosiding SNATIF, 259-266.

Nangi, J., Indrianti, S. H., \& Pramono, B. (2018). Peramalan Persediaan Obat Menggunakan Metode Triple Exponential Smoothing (Tes) (Studi Kasus: Instalasi Farmasi Rsud Kab. Muna). semanTIK, 4(1), 135-142.

Ravinder, H. V. (2013). Forecasting With Exponential Smoothing Whats The Right Smoothing Constant? Review of Business Information Systems, 17(3), 117-126. https://doi.org/10.19030/rbis.v17i3.800 1

Rossetti, R. (2019). Forecasting The Sales Of Console Games For The Italian Market. Econometrics, 23(3), 76-88. https://doi.org/10.15611/eada.2019.3.0 7

Sinaga, B., Sagala, J. R., \& Sijabat, S. (2016). Perancangan Aplikasi Peramalan Penjualan Handphone Dengan Metode Triple Exponential
Smoothing. Jurnal Mantik Penusa, 20, 359-367.

Subagyo, P. (2013). Forecasting Konsep dan Aplikasi (Ketiga). Yogyakarta: BPFE-Yogyakarta.

Tistiawan, T. A., \& Andini, T. D. (2019). Pemanfaatan Metode Triple Exponential Smoothing Dalam Peramalan Penjualan Pada PT.Dinamika Daya Segara Malang. Jurnal Ilmiah Teknologi Informasi Asia, $\quad$ 13(1), 69. https://doi.org/10.32815/jitika.v13i1.34 5

Utami, R., \& Atmojo, S. (2017). Implementasi Metode Triple Exponential Smoothing Additive Untuk Prediksi Penjualan Alat Tulis Kantor (ATK) pada " X Stationery ." Seminar Nasional Sains Dan Teknologi Terapan V, 25-30.

Wahyuni, S. N., \& Lestio, H. (2019). Implementasi Metode Triple Exponential Smoothing Untuk Perkiraan Stok BARANG. Intechno Journal, 1, 43-48. 